\title{
Mental Health Experiences of Older Adults Living with HIV: Uncertainty, Stigma, and Approaches to Resilience*
}

\author{
Charles Furlotte $^{1}$ and Karen Schwartz ${ }^{2}$
}

\begin{abstract}
RÉSUMÉ
Cette étude décrit les expériences des personnes âgées vivant avec le VIH à Ottawa en santé mentale. Onze participants âgés de 52-67 complété des entrevues personnelles approfondies. Problèmes de santé mentale sont omniprésentes dans la vie de ces personnes âgées. Nous avons identifié trois thèmes centraux communs aux histoires des participants: l'incertitude, la stigmatisation et la résilience. Pour certains de ces participants, l'incertitude impact sur la santé mentale centrée sur la survie inattendue; interprétation de l'un des symptômes; et l'incertitude médicale. Les expériences de stigmatisation des participants comprenaient la discrimination dans les interactions de soins de santé; désinformation; sentir stigmatisés en raison de certains aspects de leur apparence physique; stigmatisation aggravée; et la stigmatisation prévu. Les participants ont signalé l'utilisation de plusieurs stratégies d'adaptation, qui nous encadrent les approches à titre individuel à la résilience. Ces stratégies comprennent la réduction de l'espace VIH prend dans sa vie; faire des changements de style de vie pour accueillir sa maladie; et coopérant avec le soutien social. Ces résultats informent la compréhension des services pour les personnes vieillissantes avec le VIH qui peuvent éprouver des problèmes de santé mentale.
\end{abstract}

\section{ABSTRACT}

This study describes the mental health experiences of older adults living with HIV in Ottawa. Eleven participants aged 52 to 67 completed in-depth personal interviews. Mental health concerns pervaded the lives of these older adults. We identified three central themes common to the participants' stories: uncertainty, stigma, and resilience. For some of these participants, uncertainty impacting mental health centred on unexpected survival; interpretation of one's symptoms; and medical uncertainty. Participants' experiences of stigma included discrimination in health care interactions; misinformation; feeling stigmatized due to aspects of their physical appearance; compounded stigma; and anticipated stigma. Participants reported using several coping strategies, which we frame as individual approaches to resilience. These strategies include reducing the space that HIV takes up in one's life; making lifestyle changes to accommodate one's illness; and engaging with social support. These findings inform understandings of services for people aging with HIV who may experience mental health concerns.

1 School of Social Work at McMaster University

2 School of Social Work at Carleton University

* The first author of this manuscript was supported by a Doctoral Research Award from the Canadian Institutes of Health Research (2012-15). Thanks to Charles A. Emlet (University of Washington, Tacoma) and Lori Chambers (McMaster University) for reviewing and providing feedback on earlier versions of this manuscript.

Manuscript received: / manuscrit reçu : 16/01/15

Manuscript accepted: / manuscrit accepté : 21/09/16

Mots clés : le vieillissement, la santé mentale, la résilience, la recherche sur le VIH/qualitative

Keywords: aging, HIV / AIDS, mental health, resilience, qualitative research

La correspondance et les demandes de tire-à-part doivent être adressées à: / Correspondence and requests for offprints should be sent to:

Charles Furlotte

Ph.D. Candidate

School of Social Work

Kenneth Taylor Hall (KTH), Room 319

McMaster University

1280 Main St. West

Hamilton, ON L8S 4M4

$<$ furlotcr@mcmaster.ca> 
Aging with HIV (human immunodeficiency virus) is a steadily growing trend in Canada. Older adults living with HIV experience mental health issues influenced by psychosocial factors, and a considerable body of literature has recently emerged about how uncertainty, stigma, and resilience may shape these mental health experiences. Less research has been conducted on the individual coping strategies older adults living with HIV may use. The perceived effectiveness of mental health services available to older adults who are dealing with the continuing health impacts of HIV and AIDS (acquired immunodeficiency syndrome) has been understudied.

Our qualitative study examines the mental healthrelated experiences of 11 older adults living with HIV in Ottawa, Ontario. In this study, we asked the following question: How do individual older adults living with HIV construct their own mental health experiences? We do not prescribe standard mental health pathways; rather, we discuss the information gained in our study from people's individual narratives and describe some of their individual experiences of uncertainty, stigma, and resilience.

\section{Background}

\section{HIV and Aging}

Access to highly effective combination antiretroviral therapies (cART) means that many people living with HIV (PLWHIV) in high-income countries are experiencing improved life expectancies (Antiretroviral Therapy Cohort Collaboration, 2008; Samji et al., 2013; Squire, 2013). As a result, people are living longer and aging well into older adulthood with HIV. In 2013, 11 per cent of the PLWHIV in Canada were over the age of 50 (Public Health Agency of Canada [PHAC], 2014, p. 22). Currently, 11.4 per cent of males and 8.5 per cent of females testing positive for HIV in Canada are over age 50 (PHAC, 2014, pp. 23-24). Age 50 is now commonly used to denote "older adulthood" in the context of HIV. Fifty years may be an appropriate age cut-off that reflects some physiological aspects of aging with HIV (Blanco et al., 2012). Although there is little research on biomarkers of aging in the context of HIV, some age-related clinical syndromes are "exacerbated" by HIV (Pathai, Bajillan, Landay, \& High, 2014). HIV, in some ways, for some people, can involve premature social aging (Wallach \& Brotman, 2013).

Aging with HIV will continue to become more of an issue. Twenty-four percent of men and 17.9 per cent of women testing positive for HIV are between the ages of 40 and 49 (PHAC, 2014, pp. 23-24) and are just about to reach age 50, and newer infections among those aged 50 and older are documented to also be on the rise (PHAC, 2010). It is unknown whether Canadian numbers may come to mirror those in the United States where, as of 2015 , over half $(50 \%)$ of PLWHIV were over age 50 , with predictions indicating that this will increase to 70 per cent by 2020 (Effros et al., 2008; High et al., 2012; Senate Special Committee on Aging, 2013).

Despite improved outcomes for older adults living with HIV in Canada, HIV still remains a difficult chronic disease to live with, often involving multiple complex medical co-morbidities (Justice, 2010). Older adults living with HIV experience accompanying mental health issues (Grov, Golub, Parsons, Brennan, \& Karpiak, 2010), as well as a high degree of uncertainty (Solomon, O'Brien, Wilkins, \& Gervais, 2013) and experienced stigma (Brennan \& Karpiak, 2009; Emlet, 2006). Resilience is also suggested to be typical for some older adults living with HIV (Emlet, FredericksonGoldsen, \& Kim, 2013; Fang et al., 2015).

Next, we briefly describe mental health outcomes for this population, as well as describe research that addresses uncertainty, stigma, and resilience.

\section{Mental Health}

The Public Health Agency of Canada (PHAC, 2016) characterizes mental illnesses as "alterations in thinking, mood or behaviour associated with significant distress and impaired functioning". Mental health is broader than the absence of mental illness. It encompasses psychological and social harmony; quality of life and general well-being; self-actualization and growth; effective personal adaptation; and the mutual influences of the individual, the group, and the environment (Canadian Association of Social Workers, 2001; cited in Regehr and Glancy, 2010, p. 1).

PLWHIV may be more likely to suffer from mental health challenges, with almost one- sixth experiencing depression and one-third experiencing anxiety (Robertson et al., 2014). A growing body of literature is examining the psychosocial, mental health and behavioural issues that accompany aging with HIV (Rueda, Law, \& Rourke, 2014). A recent systematic literature review on the psychosocial aspects of aging with HIV cited depression, cognitive decline, hardiness, and resiliency as emergent themes related to mental health in research concerning this age group (Roger, Mignone, \& Kirkland, 2013).

Of concern, a variety of research studies from the United States in the past two decades observed that many older adults living with HIV experience mood disturbances with suicidal thoughts and behaviours (Grov et al., 2010; Heckman, Kockman, \& Sikkema, 2004; Heckman, Kochman, Sikkema, \& Kalichman, 1999; Karpiak, Shippy, \& Cantor, 2006). Grov et al. (2010) found a depression prevalence rate of 39 per cent 
among 914 older adults living with HIV, and that independent factors associated with depression include perceived HIV-related stigma, loneliness, and selfreported problems with memory, low energy, and younger age. Therefore, unique social factors, cognition, quality of life, and cohort effects are all likely to have an impact on the mental health outcomes of older adults living with HIV.

Older adults living with HIV may also experience neuropsychological and neurocognitive issues (Rueda et al., 2014; Wendelken \& Valcour, 2012) including general dementia, HIV-associated dementia (Valcour \& Sacktor, 2002), and other HIV-associated neurocognitive disorders (Becker, Lopez, Dew, \& Aizenstein, 2004). Wendleken and Valcour (2012) suggested that severe brain impairment is more common in older adults living with HIV. In addition, issues of substance abuse may further complicate the clinical picture for this group (Eldeman, Tetrault, \& Fiellin, 2014; Topolski, 2002).

\section{Uncertainty}

Uncertainty is a common characteristic of living with HIV (Brashers, Niedig, Reynolds, \& Haas, 1998; Rosenfeld et al., 2014; Solomon et al., 2013). It is well established that uncertainty plays a central role in the mental distress experienced by many PLWHIV (Brashers et al., 1998), although it still remains to be seen how and to what degree uncertainty plays a role in the mental health of older adults living with HIV. Given that so much of mental well-being is related to perceived control in an individual's life, it is likely a key feature.

Solomon et al.'s (2013) grounded theory study with 49 PLWHIV in Ontario reported that uncertainty emerged as a key component of aging with HIV as a disability. Uncertainty in the Solomon et al. (2013) study focused on prognosis, symptom interpretation, and practical questions of where people will live and who will care for them as they grow older with HIV. Rosenfeld et al. (2014) conducted research with 76 older adults living with HIV and their service providers as part of the HIV in Later Life Study in the United Kingdom and found that uncertainty characterized the lived experiences of older adults living with HIV themselves as well as the state of medical knowledge about aging with HIV. Together, this research shows that uncertainty can be experienced differently by individuals and demonstrates the value of individuals' stories to inform understandings of aging with HIV.

\section{Stigma}

Older adults living with HIV may experience the deleterious effects of compounded stigma. Multiple marginal social locations - such as identifying as HIV-positive; being lesbian, gay, bisexual, transgender, or queer (LGBTQ); being a member of a racial minority; living with mental illness; as well as being older adults makes this group highly vulnerable. HIV-related stigma has been defined as actions -prejudice, discounting, discrediting, and discrimination - directed at people perceived to have HIV or AIDS (Herek, 1999; Herek, Mitnick, \& Burris, 1998). HIV is considered to be the most intensely stigmatized physical condition (Crawford, 1996). HIV-related stigma can be enacted or felt (Green \& Platt, 1997), and is commonly anticipated by people living with or at risk of HIV (Golub \& Gamarel, 2013). Green and Platt (1997) suggested that HIV-related stigma encountered in people's health care interactions could be particularly fear-inducing and traumatizing.

The relationship between HIV-related stigma and mental health outcomes of older adults living with HIV has been studied previously. Heckman, Kochman, Sikkema, and Kalichman (1999) studied 113 midlife and older adults living with HIV in the United States and ascertained that those who reported elevated levels of depression tended to also experience HIV-related stigma and discrimination. Heckman, Kochman, and Sikkema (2004, p. 48) administered surveys to 83 older adults living with HIV and found stigma to be positively correlated with depression; however, their results also indicated stigma is not a significant predictor of depression. Grov et al. (2010) found that the stress of stigma experienced by older adults living with HIV might pose aversive mental health risks. Analysis of their study showed that 43 per cent of variance in depression was related to HIV-related stigma among this population. Age does not necessarily predict experiences of stigma, however. Emlet et al. (2015) reported that for PLWHIV who are also depressed, the impact of stigma might actually decline with age, but for PLWHIV who are not depressed, its impact increases to age 50 and then decreases.

The relationship between ageism, HIV-related stigma, and stigma related to mental health is not well elucidated. The co-occurrence of ageism and HIV-related stigma has been addressed only in a handful of studies. Qualitative research shows us how individuals can uniquely experience layered stigmas. Emlet (2006) conducted interviews with 36 older adults living with HIV and reported experiences involving rejection, stereotyping, fear of contagion, violations of confidentiality, and internalized ageism, noting how the majority (68\%) of participants were "doubly" stigmatized by experiencing the co-occurrence of ageism and HIV-related stigma.

Mental health stigma - that is, stigma enacted against or feared by people on the basis of their mental health 
concerns - is considered to be a factor as to why people generally do not seek mental health care (Corrigan, 2004). Previous work has been done on the "double whammy" of stigmas related to aging and mental illness (Kirby \& Keon, 2006). Stigma related to mental illness "compounds age discrimination" for older adults who experience mental health challenges (MacCourt, Wilson, \& Tourigny-Rivard, 2011, p. 30). Older adults living with HIV undoubtedly experience a combination of ageism and mental health-related stigma, along with the stigma related to living with HIV. It is unknown how these stigmas all intersect. Given the multiple ways stigma can be experienced, more research is needed with older adults living with HIV who also experience mental health concerns.

\section{Resilience}

Resilience is a popular conceptual framework used to view aging with HIV. Masten, Best, and Garmezy's (1990) study of children who overcame adversities suggests that to be resilient could include the "capacity for, or outcomes of, successful adaptation, despite challenging or threatening circumstances" (p. 426). Some work has linked resilience to aging generally, and to aging with HIV specifically.

In the Resilience in Later Life framework by Smith and Hayslip Jr. (2012), resilience is viewed as positive adaptation in the context of serious adversity experienced currently or in the past. The framework is multidimensional, taking into account the larger social context of an individual's life. Smith and Hayslip Jr. (2012) proposed that individual attributes, interpersonal relations, and supports located in a person's environment are all protective factors that foster resilience in older adulthood. These models recognize that resilience is contingent on a number of factors, and likely manifests differently among individuals. Although personal resilience may be a useful framework, its value has been criticized because of its lack of systems focus (Luthar, 2000).

Resilience frameworks have been applied to examining well-being in older adults living with HIV (Emlet et al., 2013; Emlet, Tozay, \& Raveis, 2011; Fang et al., 2015). Fang et al. (2015) developed a model-of-resilience construct drawing from data drawn from 299 older PLWHIV. This research frames resilience as consisting of coping self-efficacy, active coping, hope and optimism, and social support, which are all argued to reduce the negative influence of life stress on physical, emotional, and overall well-being.

Emlet et al. (2011) found evidence of a high degree of resiliency among 25 older adults living with HIV. The authors observed that protective factors such as personal outlooks and characteristics, as well as family and community supports, may help "buffer" against adverse life events and promote adaptation (p. 102). Emlet et al.'s (2013) study with 226 HIV-positive gay and bisexual men also showed that social support was a protective factor on mental health-related quality of life.

Some research has linked resilience experienced by older adults living with HIV to successful aging paradigms, suggesting that resilience is a factor in coping strategies used to age well with HIV (Emlet, Harris, Furlotte, Brennan, \& Pierpaoli, in press). Individual approaches to resilience reported in the stories of older adults living with HIV can inform understandings of resilience within this largely marginalized population.

\section{Methodology}

Relatively little information is yet available about the mental health experiences of older adults living with HIV and particularly with regard to PLWHIV in the province of Ontario. The perspectives of older adults living with HIV who also report mental health challenges are important. Our study was guided by the life course perspective that attends to diversity of an individual's life trajectories and personal stories (Hutchinson, 2005). Older adults living with HIV likely experience psychosocial challenges similar to older adults who are not living with HIV, but may not have the same resources (because of stigma and systemic discrimination) to deal with them. As life expectancy increases, we can expect there to be greater numbers of older adults living with HIV who require mental health services.

\section{Design}

The analysis discussed here is part of a larger study carried out by Furlotte (2009), which broadly addressed health and social service experiences of older adults living with HIV/AIDS in Ottawa. The study featured in this article was based on the first author's master's thesis research (Furlotte, 2009), which was supervised by the second author. We previously reported on findings from data collected for this project related to housing experiences of the study participants (Furlotte, Schwartz, Koornstra, \& Naster, 2012). The study was approved by the Carleton University Research Ethics Committee. We recruited older adults living with HIV in 2007, using posters we strategically placed at a local AIDS service organization (ASO) and by referral to the project by ASO staff. All participants reported attending open drop-in services at the local ASO. We recruited participants aged 50 and older to be consistent with other Canadian and international research on the topic of aging with HIV/AIDS. We conducted semi-structured interviews in Ottawa, 
a mid-sized urban centre that made up 13 per cent of new HIV diagnoses in Ontario at the time of the interviews (Remis, Swantee, \& Liu, 2009, p. 33). Participants self-reported on their HIV status and age, and there were no other inclusion or exclusion criteria.

\section{Procedures}

Participants of the study provided informed consent, completed a demographics questionnaire, and filled out a checklist of health and social services they had used. We collected qualitative data through audio-recorded interviews that the first author conducted. An interview guide listing potential topics - including aging with HIV, mental health, and social support - guided the exploratory conversations. Our interview guide contained questions such as "Can you discuss your experiences with aging?" and "How do you feel about your personal mental health?" We offered participants an honorarium of $\$ 20 \mathrm{CAD}$ to participate.

\section{Demographics}

The study sample consisted of 11 older adults in Ottawa living with HIV/AIDS. Below, we present basic demographic information about these participants including information about their housing, living situations, and health statuses.

The sample consisted of two women and nine men, with an age range of 52 to 67 years $(M=60)$. The participants were mostly of European ancestry: White, English speaking, well-educated adults who attained a high school education or higher, with varying incomes, housing and work histories, sexual orientation, and relationship statuses. Participants self-identified as gay, bisexual, straight, or two-spirited - that is, a person of both masculine and feminine spirit, as per indigenous Aboriginal beliefs. Of the 10 participants who self-identified as retired, the mean length of time since retirement was 11 years. Six of the participants reported that they were HIV-positive and asymptomatic, two reported experiencing active symptoms, one reported having progressed to AIDS, and two reported that they did not know the progression of their HIV infection. The majority of participants (eight) had known they were HIV-positive for 10 years or more; and none had known of their status for fewer than five years. Seven participants learned of their HIV status in midlife, after age 45 .

The majority of these participants (eight) lived alone. Two participants reported living with family. Two reported homelessness. Four reported that they owned or mortgaged their own home, and three reported renting a unit. Some participants characterized their housing status as precarious, which was reported in Furlotte et al. (2012). Five participants reported receiving Ontario Disability Support Program benefits. Six reported receiving benefits from the Canada Pension Plan (or Quebec Pension Plan). Three reported receiving private pension benefits.

\section{Analysis}

We used a plan of thematic analysis adapted from Tutty, Rothery, and Grinnell's (1996) qualitative research guide to analyse transcripts. We conducted a priori, or theoretically driven, coding, drawing on broad theoretical conceptualizations commonly believed to be associated with aging with HIV, including stigma, uncertainty, and resilience. These conceptualizations sensitized our analysis, and helped us to identify properties that characterize the central themes of the study.

The first author conducted first-level coding by previewing the data, developing a set of topics, assigning each topic a different colour code, identifying meaning units (sections of interviews containing words, sentences, and statements the first author deemed were relevant to particular themes) and then refining these categories (Tutty et al., 1996, p. 97). Overarching codes initially assigned by the first author included those to indicate aging, mental health, stigma, and social support.

The authors developed a process of second-level coding which included getting a global sense of how themes were discussed in each individual interview, re-reading, fleshing out the properties associated with each theme (noting similarities and differences between participants), and tying our findings to existing literature. The first author compiled coded data into text documents organized by theme (Tutty et al., 1996, p. 107). Peer debriefing was conducted between the authors concerning methodology, project progress, interpretation, and consensus of themes, and journal entries and memos were created during and after each interview (p. 98). Later in the process, the first author selected sections of individual participants' stories that best illustrated properties that represented themes of uncertainty, stigma, and resilience in the sample.

\section{Findings}

Participants reported histories with a variety of mental health issues. Notably - out of our sample of 11 - six participants self-reported diagnoses of mood disorders (four reported clinical depression; two reported having been diagnosed with bipolar disorder), and three mentioned substance use issues across their lives, which they framed as problematic. Previous traumatic experiences were common in many of the participants' stories. Some participants discussed contemplating suicide 
earlier in their lives, and the two women in this study reported they had attempted suicide at least once.

Engagement with the mental health system was common for these participants. They reported using a variety of mental health services, including various mental health therapists, self-help groups, and hospitals. All participants reported attending open drop-in services at local ASOs, with eight participants reporting to have used peer-based HIV support groups there. Five participants reported using mental health and counselling services (including psychiatrists, psychologists, social workers, and counsellors), five did not, and one indicated an inability to access counselling. Moreover, a small portion of this sample had access to institutional services (three participants used the services of a social worker, one indicated they needed but could not get a social worker, and three used case management services). Additionally, four participants noted that they accessed spiritual services in the Christian tradition. Notably, only one participant reported accessing seniors' services.

Our findings section presents the stories that illustrate how the themes of uncertainty, stigma, and resilience underpin mental health experiences of older adults as they age with HIV. Uncertainty in the lives of participants included unexpected survival; interpreting one's symptoms; and medical uncertainty. Evidence of stigma included stories that described discrimination in health care interactions; stigmatized physical appearances; compounded stigma; and anticipated stigma. Participants also described individual approaches to achieving resilience, which draw on strategies that include reducing the mental space HIV takes up in one's life; changing lifestyle to accommodate HIV; and actively engaging with social support (see Table 1). Pseudonyms were used to protect the anonymity of the participants.

\section{Uncertainty}

Participants' stories were underpinned by uncertainty. Three properties were associated with this category: unexpected survival; interpreting one's symptoms; and medical uncertainty.

Timothy, 52, described experiencing uncertainty about his unexpected survival, which he reported involved preparing for death that never came. Timothy explained how unexpectedly surviving an AIDS diagnosis in the 1980s and reaching his fifties has shaped his experience of depression:

I was preparing to die and it didn't happen, so it came out as a loss. I was having a reactive depression, I believe, because of preparing to go to this place and then it never happened. It was almost
Table 1: Major themes and associated issues in mental health experiences

\begin{tabular}{|c|c|}
\hline Theme & Participant-identified issues \\
\hline Uncertainty & $\begin{array}{l}\text { Unexpected survival } \\
\text { Interpreting one's symptoms } \\
\text { Medical uncertainty }\end{array}$ \\
\hline Stigma & $\begin{array}{l}\text { Discrimination in health care interactions } \\
\text { Misinformation } \\
\text { Physical appearance } \\
\text { Compounded stigma } \\
\text { Anticipated stigma }\end{array}$ \\
\hline $\begin{array}{l}\text { Approaches to } \\
\text { resilience }\end{array}$ & $\begin{array}{l}\text { Reducing space that HIV takes up in one's life } \\
\text { Accommodating HIV } \\
\text { Engaging with social support }\end{array}$ \\
\hline
\end{tabular}

like it was another loss, like losing somebody, losing your job or losing your health status, you know ... [l'm] having feelings, depression but also a little bit of anger coming out.

Timothy noted that not dying actually came out as another loss in a long series of personal losses. Following the death of so many others - including Timothy's partner - at the height of the AIDS crisis in Ontario, he anticipated his own death would quickly follow, and instead has found himself surprised and perplexed that he survived and is aging with HIV. He used the term "reactive depression" to describe the fallout and anger he experienced that accompanies unexpectedly surviving with HIV. Timothy, who also reported living with depression and bipolar disorder for several years, reported that he had been receiving the services of a hospital psychiatrist as well as a peer bereavement group for PLWHIV.

Participants reported uncertainty about interpreting their day-to-day health symptoms. Daisy, 62, reported anxiety over interpreting cognitive decline as she aged with HIV disease, noting that she had experienced problems with her memory of recent events, as well as periodic mental "blackouts". Daisy observed that "the part about getting old that worries me is my mind. That worries me. I think my memory is more a bother to me than anything else." Daisy mentioned the uncertainty she experienced around the ambiguous causes of her cognitive changes. She described her interpretations of her recent memory loss:

I call it a senior moment when I forget things, whether it's HIV-related or just the fact that I'm turning 62. I don't know if it's related; I mean, I'm hoping that it's not. If that's the case then I would worry even more as I get older and my T-cells don't climb as high as I'd like them to, that something will happen with my brain.

In working through the uncertainties of HIV and its impact on her cognitive function, Daisy reported that 
she was somewhat confident that age was the culprit, yet the cause of her memory loss was ultimately unknowable. Because of this uncertainty, Daisy reported she cautiously monitored her T-cell counts, an important laboratory indicator of how well her immune system functioned and which could predict HIV disease progression.

Daisy's interpretations about her cognitive decline were grounded in her experience with brain damage her ex-husband reportedly suffered before his death a few years before, which added to her anxiety about being uncertain of HIV's impact on her own aging brain:

When my husband became very ill, his illness was HIV-related, and his brain swelled ... that's hard for me because I have to ask myself, "Is that ever going to happen to me, does that happen to most HIV clients as they get older?" That the virus will spread ... I don't know where it's hidden. I don't care if it's hidden in my crotch, under my arm, or behind my ears. What worries me is: Is there a virus part that's hidden in my brain?

Daisy seemed to link her own brain changes with HIV to her ex's disease trajectory and neurological complications. Daisy's concern about where in her body the HIV may have formed hidden reservoirs illustrates how current medical knowledge can inform older adults living with HIV about what to expect as they age with HIV only up to a certain point, since the impact of viral reservoirs is not yet fully understood, and their possible impact on cognitive aging remains understudied.

Timothy's concerns about how to interpret energy levels also refer to uncertainty about health symptom interpretation. He asked:

Are energy levels affected because we're just older? Is it also affected by my mood and depression, or is it also affected by my HIV status and general well-being? But, you know, I do find for whatever reason that it's harder to come up with energy to get engaged in more things.

Like other participants, Timothy reported being uncertain about whether diminished energy levels were a result of HIV disease, aging, his general health, or depression - which can occlude attempts to address the issue medically for older adults living with HIV (Rosenfeld et al., 2014).

Violet, 62, reflected on a session with her therapist that illustrates how uncertainty might relate to interpreting her symptoms of depression:

When it came time to slowly stop talking about my distress but start talking about my reality - a totally different thing. It was really weird because the psychologist would say, "Look at the conversation that we're having, are we talking about this because you are a woman? Are we talking about this because you are over 50? Or are we talking about this because you are HIV-positive?" and it wasn't clear anymore.

For Violet, several possibilities likely contributed to her distress, including but not necessarily only her HIV diagnosis. This ambiguity produces uncertainty for both her and her therapist. This finding illustrates how the uncertainty of interpreting one's symptoms extends to psychological symptoms experienced by some older adults living with HIV.

Medical uncertainty is often encountered in health care interactions, and this causes stress for patients and practitioners alike. Medical uncertainty was a common observation mentioned by the participants. Wesley, age 66, identified as a two-spirit Aboriginal man who had previously been diagnosed with bipolar disorder, and AIDS-related dementia. He noted medical uncertainty in his account of being initially misdiagnosed with Alzheimer's disease (AD). Wesley experienced a profound degradation of his cognitive capacities in his late forties, and in the 1990s was misdiagnosed as having early onset $\mathrm{AD}$, which has since been re-diagnosed as HIV-associated dementia. He provided a detailed account of this experience:

I've been diagnosed as having a rapidly advancing case of early onset Alzheimer's, because I was losing my memory system ... I had something that looked like that, it looked like that because it continued to get worse. I went into a mode where I was hallucinating very badly and getting lost and not knowing where I was, needed a lot of attention and then it gradually seemed to bottom out and I gradually started to get better again.

Wesley, who reported that his HIV was controlled, and he enjoyed good personal mental health at the time of our interview, reflected on his history of receiving care from various mental health professionals over decades. He reported that his doctors "were trying to treat something that wasn't the problem". He elaborated:
I didn't have a rapidly advancing case of early onset Alzheimer's. I had one of the initial cases of what they now would call AIDS-induced dementia [sic], because over the years it has got better. I don't have it anymore. So, Alzheimer's - it wouldn't have got better.

His story about being misdiagnosed demonstrates the trickiness of differential diagnoses of cognitive disorders in older adults living with HIV, and how both participants and their health care professionals can experience medical uncertainty about elements of their care. This story is an important illustration 
of how Wesley experienced the uncertainly in medical knowledge about aging with HIV.

\section{Stigma}

Most of the study participants spoke about the mental burden of having been stigmatized because of their HIV status by family members, romantic partners, friends, colleagues, health care providers, law enforcement officials, housing agencies, and insurance companies. The experience of stigma likely contributes to mental distress. Five properties that were associated with the category were as follows: (a) discrimination; (b) misinformation; (c) physical appearance; (d) compounded stigma; and (e) anticipated stigma.

Daisy described having experienced overt discrimination based on HIV-related stigma during an interaction with hospital staff:

\section{I went in to have my surgery; one of the nurses commented, "Oh, I don't want to change her."... And I said: "You don't have to change me at all. I can go change myself, if that's how you feel." I was really upset. You're wearing gloves, what more do you need? Put a mask on if that's how scared you feel. I don't care, put an extra coat on. I really don't give a shit. But I'm a patient here, you took an oath to look after us and not discriminate!}

Daisy's experience of discrimination was emotionally upsetting for her. This story illustrates how Daisy picked up on stigma related to her condition during a health care interaction, and how she resisted this inappropriate treatment. Daisy recounted that on another occasion, she was stigmatized by her health care provider after disclosing that she had once been raped, and this made her "feel really unclean". She describes the impact this had on her sense of self-worth:

\begin{abstract}
[After what] the doctor said I really considered myself dirty. What I had was a dirty stain and I couldn't get rid of it for the longest time, until I met my partner that I have today. That makes me feel a lot better. I have realized now that I am not dirty.
\end{abstract}

This finding supports Goffman's (1963) original observation that stigma involves a social spoilage, a phenomenon particularly experienced by being judged or labelled as "dirty" or "unclean" based on an individual's HIV status. It also illustrates how stigma can be internalized, in that people come to hold stigmatized beliefs about themselves.

Jimmy, 57, who is gay, also recalled being stigmatized by his physician, because of his sexual practices. He observed that his sex life was scrutinized by health care professionals, some of whom lacked realistic understandings of gay intimacies, like the meaning and value of sex without a protective barrier. Jimmy reported that despite that his HIV infection was wellcontrolled with medication; his provider pressured him to use condoms even for oral sex, although this is not a realistic expectation for some gay men. He noted: "Our lifestyle is freestyle and erotic, and there are a lot of social psychologists and stuff like that who are just not trained in dealing with it."

Misinformation about HIV persists today, fuelling stigma. HIV was once thought of as an irreversible death sentence. George, 66, remembered overhearing a telephone conversation between his physician and a local public health unit official, who discourteously asked "Is that guy still alive?" within earshot of him. He recalls hearing the physician respond, "Yes, he is sitting right in front of me, doing quite well." George, a long-term survivor, reported that he felt offended by their exchange, noting that, because of effective treatments, HIV is no longer the death sentence it once was. His encounter suggests that health care providers play an important role in shaping an individual's construction of their HIV prognosis, and that misinformation can contribute to HIV-related stigma.

George, who is also gay, also revealed that he experienced stigma when he sought professional mental health treatment. In particular, he reported that one provider's lack of understanding about his sexuality and family history discouraged him from seeking further services:
The psychologist couldn't understand the fact that I was married and I had a child but I was still gay; she couldn't understand that. She kept asking ques- tions about it. Well, it's quite common to have been married with children and still [be] gay.

George perceived that his service provider stigmatized him for not falling into a predictable category of sexuality, and lacked acceptance of diversity needed to work with members of LGBTQ communities.

Some long-term survivors in particular reported that they felt stigmatized because of visible changes to their body shapes and aspects of their physical appearances. Common visible symptoms that accompany HIV may include facial wasting, weight gain, and lipodystrophy (or "Buffalo hump"), a devastating redistribution of body fat that results in physical aesthetics that cause psychological hardship and perceived judgment from others. Violet, 61, reported going through a "psychological hell" of depression that followed her HIV diagnosis and culminated in several attempts to end her life. Violet reflected on how her mental health deteriorated after she started to experience visible physical symptoms as side effects from antiretroviral medication: 
I never thought of it [HIV] as being that big of a deal until I took the medication and [experienced] diarrhoea and lipodystrophy, and then it became a depression and suicidal tendencies - [HIV] became a big deal after that.

Jimmy also refers to how being marked or identified as HIV-positive through visible physical attributes (such as wasting syndrome and lipodystrophy) can contribute to social exclusion of older gay PLWHIV within larger social networks of gay men. He reported:

I can spot someone who is HIV-positive now. Especially the old timers. Just like back in the old days, you could tell someone who was living with AIDS back then. But that should not be a discriminatory factor amongst ourselves; we should be able to go out, you know? It's such hypocrisy, it's such a denial, and it's such a denial of who you are, especially when you are living with HIV.

Barriers such as denialism of HIV-positive men within gay communities and stigma related to identifiable physical attributes are of concern. Jimmy's comment about the treatment of "old timers" illustrates the confluence of HIV-related stigma and ageism within gay communities, which can subject older adults living with HIV to rejection and social isolation.

Compounded stigma, related to intersecting aspects of participants' identities, were reported during our study. Timothy, a gay man, observed that experiencing disability associated with HIV did eat away at his sense of self-worth, which was further exacerbated by his mental health concerns:

\begin{abstract}
Always there's been these feelings of your selfworth, of your ability of being able to contribute to society, and so it's really compounded when you're on disability [benefits] because of HIV. So it's really the physicality of it that has you on a disability, but yet, you have mental health issues on top of that, so you know ... the depression thoughts [sic] come in there, the low, the blues, the low emotions, and so they all sort of work on the self-worth a little bit and being compounded by the fact that, you know, you're already on a disability and feeling slightly vulnerable.
\end{abstract}

The "compounded" nature of Timothy's distress speaks to the layered or intersectional nature of the stigma he experienced related to living with HIV, being gay, having mental health issues, and also receiving social disability benefits. This story furthers our understandings of intersectionality (Hill Collins, 1998) as it concerns older adults living with HIV. To Timothy, stigma related to mental health status was actually more restrictive than stigma related to HIV:

I certainly feel restricted talking about both issues ... but if I am going to open up about anything,
I'm probably going to open up about my HIV status more than my mental health status. I find, for me, I have self-stigmatized, I guess, on mental health more than HIV.

It is interesting that the stigma Timothy felt about living with a mental health issue was more pronounced than stigma related to having HIV. He noted that he "self-stigmatize[d]" or internalized stigma related to his mood disorder more than his HIV status.

Together, these stories illustrate how older adults living with HIV may further experience multiple layers of compounded stigma. These stories also help make visible how stigma related to disability, mental health issues, and sexuality affect well-being and service use (Corrigan, 2004).

Some participants reported that in addition to the stigma they already encountered in their everyday lives, they also anticipated further stigma, and this could sometimes present a serious barrier to disclosing their HIV status. Violet described a recent experience in an infectious disease clinic at her local hospital:

I'm waiting and I don't dare look at anyone else in the waiting room, because they might recognize me or I might recognize them, or you know, the uncomfortable feeling that you have when you are at the waiting room, and then the nurse would cry out "[Participant's full name], Room 4." And I'm going "Oh, how she could do that? She just told everybody my name!" So for the first 2 years I kept telling them "Don't use my [sur] name, just say [my first name].

Violet referred to an "uncomfortable feeling" of anxiety, that for her characterized anticipating HIVrelated stigma. Violet's fear of stigmatization was so severe that she requested her family name not be used in public.

Timothy also reported he anticipated further stigma, but for him that was related more to his mental health than HIV status, particularly within the services he accessed at AIDS service organizations. For instance, he noted that while the HIV/AIDS bereavement support group he attended helped to offset the impact of local therapist shortages, it was "a little uncomfortable talking about mental health issues there". Given the self-stigma Timothy experienced, he did not feel safe opening up about his mental health issues, even to a group of HIV-positive peers who might also routinely encounter stigma. Timothy feared he would encounter worse stigma if he disclosed about his mental health issues. In this regard, peer support groups intended to decrease stigma for older adults living with HIV do not replace formal services such as individual counselling or make up for their absence. 
Despite these experiences with stigma, some people reported resisting it, like Daisy who fought for her right to care with hospital staff, and Jimmy who challenged sexual stigma with his physician. In contrast, Violet, George, and Timothy did not report this type of resistance in their encounters with stigma, and participants in our study did differ on this.

\section{Approaches to Resilience}

Although our findings indicate that uncertainty and stigma certainly impede the mental health of older adults living with HIV, we also noted various approaches to resilience that individuals use to cope. Resilience took on many forms for individual study participants, especially following the occurrence of adverse events in their lives. The theme of resilience consists of three properties: Reducing the "space" HIV takes up in one's life; changing lifestyle to accommodate HIV; and actively engaging with sources of social support.

Some participants in the study reported employing intrinsic strategies to cope, such as choosing to reduce the mental space HIV takes up in one's life. Despite experiencing depression characterised by days when he lacked energy to get up out of bed or pursue his interests in painting and playing music, George reported using an intrinsic mental strategy of minimizing the space HIV took up in his life to cope with aging with HIV: "I try not to engross myself with the virus because if I do, it consumes me". Through not engrossing himself with his HIV disease, George was able to focus on other areas of his life, and live more broadly. Violet also spoke of the space she let HIV take up in her life:
My life is a pie, and HIV is only one piece of the pie ... the first 3 years that I was HIV [positive] it was the pie, and for some people it's still the pie. It's just one part. There are so many things to life, more than HIV.

Participants noted that making changes to their lifestyle helped them to be resilient to the challenges of aging with HIV. Violet, who previously discussed the negative experience she endured following her diagnosis, offered the following advice for others who may be coping and managing chronic pain: "If I have the right attitude the pain is definitely not as harsh." She elaborated:

\footnotetext{
I've taken a positive constructive approach to my aches and pains ... I just take it for what it is, and I change my schedule to accommodate my body that needs to be resting, and so it hasn't -like I haven't suffered. I have suffered so much psychologically that physically there is nothing that can be as bad as the psychological hell I went through, so right now I'm in a good place.
}

Violet's story suggests that by incorporating the proper amount of rest and balance into her schedule, she could accommodate HIV disease and offset some of the physical ailments of aging with the virus through lifestyle change. By situating her chronic pain in context of the psychological anguish she had experienced post-diagnosis, Violet's story provides further evidence of resilience.

Daisy, like many of the participants, was a longtime volunteer and AIDS activist. She also spoke of the importance of achieving "balance" to accommodate HIV, which, for her, was achieved by trying to maintain a comfortable pace for everyday activities:

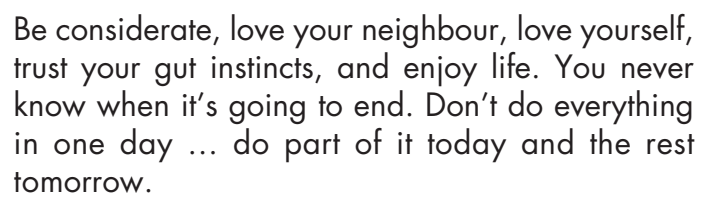

Daisy's approach to coping suggests that resilience in aging with HIV involves connecting with others, loving oneself, and intuitiveness, and making lifestyle changes to balance the pace of life's activities to accommodate HIV.

Participants noted that they sought and received various kinds of social support that affected their quality of life and helped foster resilience. Daisy noted how beneficial her proximity to her family (including her new partner, her children, and grandchildren) was to maintaining her personal mental health. George mentioned that he derived support from a group of peers consisting of other older gay men: ("that's when I talk about my depression, about the quality in my life"). George viewed peer groups as safe spaces to discuss mental health, whereas Timothy's struggles with mental health stigma, which we mentioned earlier, precluded him from disclosing his mental illness. Timothy, Jimmy, and George all noted the importance of families of choice, or fictive kin; largely networks of gay men. Many of these men endured multiple losses at the height of AIDS-related deaths within their communities. For some participants, these losses spurred isolation and depression, and for others, activism. In addition to fictive kin, Violet, Phillippe, and Caleb discussed the positive role spiritual support played in coping with the challenges of living with HIV.

Jimmy's personal approach to resilience involved making changes in his life so that he could actively manage his social support network:

To me, you never stop learning, you never stop redeveloping yourself. I call it tweaking and in the last 6 months, I have been re-tweaking my life. I re-evaluate myself a lot of times, I say "Ok, what's bugging me, who's a pain in the ass in my life?"... I don't put up with shit anymore. 
Jimmy made note of how "tweaking" elements of his life and evaluating his social network contribute to resilience as he ages with HIV. In addition to being selective with the people in his life, Jimmy discussed the importance of participating in AIDS activism and community volunteerism as coping mechanisms that helped him grow out of original despair about having HIV. He also reflected on the importance of his journey towards adopting an outlook of balancing the needs of others with his own self-care:

I've learned to take care of me, I've learned to say "No", 'cause a lot of us again are caregivers, a lot of us take a back seat; we seem to have that thing within us, you know, to care. I've learned now to take care.

In learning how to "take care" and say "No" in order to set healthier boundaries and prioritize his own needs, Jimmy is able to better cope with HIV. He observed how HIV has empowered him and how this has shaped his outlook and character: "That's what HIV did for me, rather than - you know, the old expression, "What doesn't kill you makes you stronger?" - well, this has made me a different individual, it's made me who I am today".

Participants frequently mentioned that formal social support services were also preservative and helpful. Illustrating the importance of access to the appropriate care at the right time, Violet recalled, "A very key point in my survival was that psychologist that I saw." Conversely, there were also instances in which participants described mental health supports negatively. For instance, Wesley recounted the response of service providers to his condition:

I would be going along doing fine and then all of a sudden someone in the mental health system would decide I wasn't doing fine and I'd end up back in the psychiatric hospital again, but to me I was doing just fine and finally I left that province to get away from them and everything has been fine ever since.

Wesley's history of psychiatric treatment and clear distrust of the mental health system, and having to change provinces to avoid it, suggests that he achieved resilience despite his negative experiences. Together, these stories illustrate the importance of both intrinsic and extrinsic factors that these participants use to achieve resilience.

\section{Discussion}

In sum, our findings suggest that older adults living with HIV may experience uncertainty and stigma that can contribute to mental distress, although the impact of mental distress can sometimes be ameliorated through positive resilience strategies. While we do not claim to identify relationships among our three central themes - uncertainty, stigma, and resilience - our study makes visible the power of resilience in the context of uncertainty and stigma that older adults living with HIV experience daily. As per the life course perspective (Hutchinson, 2005), this study shows the value of individual narratives to understanding the various ways that uncertainty, stigma, and resilience factor into the lives of diverse older adults living with HIV.

The focus of the exploratory parent study about HIV and aging and service use in Ottawa, on which this article is based, was not mental health per se, although we approached the project with community-informed evidence (based on consultation with key informants) that mental health would be an important topic to cover. This was indeed the case. Consequently, it is interesting to consider that the majority of the participants in this study - a study that was not recruiting specifically for mental health issues - reported such histories and experiences. Participants were very forthcoming with mental health stories, and these stories could help to fill gaps in describing characteristics of depression among older adults living with HIV.

Our findings further support existing understandings of how uncertainty, as a key concept, manifests among older adults living with HIV (Rosenfeld et al., 2014; Solomon et al., 2013). Uncertainty occurs around unexpectedly surviving long-term with HIV, which was once unimaginable; as well, uncertainty develops through interpreting one's own symptoms. Much of this uncertainty occurs within a context of incomplete and new medical knowledge about what to expect while aging with HIV. It is noteworthy that our study makes more visible the experiences of participants who have reported a high degree of mental burden, and also a high degree of uncertainty. Some of the participants' stories illustrate how uncertainty contributes to mental distress.

At least one participant, Timothy, found himself grappling with the expectation of imminent death, or "preparing to go to this place and then it never happened". Timothy's story makes visible how the uncertainty of shifting prognoses over time, and the altered life expectancy that accompanies these shifts, may "shatter" expectations of death for some long-term survivors (Davies, 1997). Similar findings have been recently reported elsewhere (Owen \& Catalan, 2012). Timothy's story adds to our understanding of some of the more consequential aspects of the phenomenon of bouncing back from HIV infection, also known as the "Lazarus effect" (Scott \& Constantine, 1999). We argue that these common types of experiences that accompany improved prognosis add to the lived 
uncertainty of aging with HIV. Altered time perspectives about the future may help shape an individual's previous orientation to "finitude" (Rinken, 2000). Accordingly, conceptualizations of time and revised life expectancy should be factored into future research on aging with HIV.

Participants' interpretations of their own symptoms and the sense of ambiguity that accompanies their conditions is a constant source of uncertainty for older adults living with HIV (Siegel, Dean, \& Scrimshaw, 1999; Siegel, Scrimshaw, \& Dean, 1999; Solomon et al., 2013). Our findings illustrate how this ambiguity extends to both physical and psychological symptoms such as cognitive issues and mental distress - and help to make visible how professional service providers may also face uncertainty in attributing causes of symptoms experienced by older adults living with HIV. For instance, Wesley's story of being misdiagnosed with Alzheimer's disease is an important illustration of the uncertainty in contemporary medical knowledge about aging with HIV (Rosenfeld et al., 2014).

Other research has noted that older adults living with HIV are uncertain about the care they will receive (Solomon et al., 2013; Furlotte et al., 2012). Based on these findings, services to assist older adults living with HIV could be improved, especially in areas of access and competencies. Participants made reference to difficulty in accessing mental health professionals. As some participants' stories suggest, competence in working with LGBTQ people is an important issue for these older adults. An understanding of the issues that affect LGBTQ communities, including openness to lesser-dominant expressions of sexuality, are particularly important. Future research should aim to better understand perceptions of the quality of the services PLWHIV receive. Overall, these participants have had to come to terms with various kinds of uncertainty, which contributes to their sense of resilience. PLWHIV's unique ways of coping with uncertainty should be further examined in future research, because tolerating or accepting uncertainty may well be an important strength or resource.

Stigma was another common theme represented in previous research and in our study findings. Participants reported having experienced overt discrimination in some of their health care interactions, as has been previously documented to be common for PLWHIV (Green \& Platt, 1997). Stigma was experienced based on misinformation about HIV, such as the belief that it is a death sentence. We know that, in the West, this is no longer the case, and that people living with HIV can lead long lives well into older adulthood (Squire, 2013). Being marked or identified as HIVpositive through visible physical attributes (such as wasting syndrome and lipodystrophy) can contribute to social exclusion, particularly within gay men's social networks. Participants also reported anticipating that they would be re-stigmatized in the future a common finding among this population that was reported previously (Golub \& Gamarel, 2013). These participants commonly noted how stigma impacted their sense of self-worth. Moreover, participants' reports may reflect a view in society that PLWHIV are inherently prone to being depressed, which would suggest further evidence of internalized oppression.

Participants reported experiencing "compounded" stigma. The concept of layering of stigmas is useful to understand how intersecting social locations construct the realities of older adults living with HIV (Emlet, 2006). Participants were vulnerable to being discriminated against on the basis of their gender, age, HIV status, mental health status, sexual orientation, race, and class. These data suggest that stigmas attached to mental illnesses and disabilities exacerbate the already daunting challenge of the compounded stigma associated with aging with HIV.

Resilience strategies were raised by the participants when asked about aging with HIV. Resilience stems from endured suffering and loss across participants' unique life courses, and likely affects the way people cope with HIV in later life. Participants in our study discussed their own experiences with adversity suicide, rape, alienation of (and from within) the gay community, and being mistreated by service providers all negative experiences to which they reported having to adapt. For some of the participants, resilience and coping strategies such as changing one's outlook, making lifestyle changes, seeking balance, and engaging with social supports mitigate despair despite their adverse experiences of living with HIV (and, in some cases, an AIDS diagnosis), as well as with previous mental health issues and getting older. Our findings are consistent with other research findings that people living with chronic illness often reorder their schedules and lifestyles to accommodate disease (Charmaz, 1991). Overall, these findings are consistent with research suggesting the importance of both intrinsic factors (e.g., personal characteristics) and extrinsic factors (e.g., social support) for older PLWHIV (Emlet et al., 2013; Mavandadi, Zanjani, Ten Have, \& Oslin, 2009).

Participants reported strategies that reflect resiliencies of older adults living with HIV previously noted in the literature (Emlet et al., in press; Emlet et al., 2011). Strategies used by these participants included engaging with social supports, managing their social networks, changing one's outlook, and adapting lifestyle changes, such as maintaining a good balance between rest and activity to better accommodate living with the effects 
of HIV. Participants also noted they achieved self-care through, for example, spiritual practices, yoga, and sport.

Formal social support is important. Participants singled out and valued the psychological services provided to PLWHIV in Ottawa, which have since been cut (Ascah, 2015). Older adults living with HIV are marginalized and experience reduced visibility, partly related to the fact that people think the AIDS crisis is largely over (Leland, 2013). This type of thinking puts everyone more at risk. In addition, a common trend across the HIV sector in Ontario has been to download responsibilities for coping and mental health support onto AIDS service organizations and peer programming initiatives, which do not always have sufficient infrastructure (Cain et al., 2013). Since funding is based on government policy and available monies, policies that address HIV / AIDS in Canada may overlook the mental health burden of the epidemic and function based on cost containment strategies, thus leaving aging PLWHIV without mental health services that have worked well in the past.

\section{Limitations}

Our study does have several limitations. As a function of the recruitment strategy we employed, all the participants attended drop-in services at their local AIDS service organization. This reflects a limitation in that those who were truly isolated could not have shown up in the study sample. As this was a qualitative study that focused on individuals' experiences, this sample is unlikely to be typical of all older adults living with HIV in Ottawa or elsewhere, but it may be typical of PLWHIV who access services or who are likely to be referred for this kind of study by case managers. The participants' common usage of and engagement with HIV / AIDS-related services that we have reported is unsurprising inasmuch as this is a feature of how we obtained this sample. We were not able to speak with people who did not have access to services in Ottawa, and thus our sample is likely biased to people connected with local AIDS service organizations.

Our data were collected more than nine years ago, and considerable gains in structural supports for older PLWHIV in Canada have begun to occur since that time. Although these data are becoming older, there is still great value of these participants' stories, which address mental health issues and needs that persist today. Given the nascent nature of Canadian data on aging with HIV, reporting these findings is important to help fill the gap of research in this area.

This exploratory study did not collect complete mental health histories of each participant, and we cannot claim to have collected information about individuals' backgrounds and experiences in entirety. It is unknown, for instance, whether participants who indicated psychiatric diagnoses experienced mental health concerns (or accessed mental health services) before or after they were diagnosed with HIV. Future research should focus on mental health histories of older adults living with HIV to better help elucidate the links between HIV, aging, and mental health.

\section{Conclusions and Recommendations}

We argue, like others, that understanding the role of uncertainty, stigma, and resilience is important, since these factors may very well contribute to mental health for older adults living with HIV. Because uncertainty depends largely on the state of medical knowledge about aging in the context of HIV, we frame personal uncertainty in relation to broader social institutions, such as our health care system. In addition to individuallevel interventions, broader structural interventions can help address uncertainty and stigma, and foster resilience, as evidenced by participants' engagement with their local AIDS service organizations.

Resilience frameworks that address older adulthood may need to be "tweaked" (to use Jimmy's word) to suit the unique experiences of older adults living with HIV. Intrinsic and extrinsic factors should be addressed by more interventions that build personal capacity for mastery, coping skills, and engaging with social support. The individual approaches to resilience noted by the participants of this study can be shared through peer and professional supports. Future research may want to address how indigenous understandings of strength and resiliency factor into the lives of Aboriginal older adults living with HIV (Brennan et al., 2015).

More dialogue is needed between existing psychological resilience frameworks and frameworks that describe social resistance to access barriers. For instance, we wonder, does psychological resilience and good mental health relate to people's being better positioned to be able to advocate for themselves? It remains unclear if participants' resilience aids in their navigating mental health services within an eroding social welfare system. Some of the participants explicitly politicized and problematized their current experiences with the mental health system, and advocated for improved services. It is unknown to what degree the critical comments they received compelled them to advocate for themselves politically, or how this related to their resilience.

It is also useful to frame mental health issues as responses to oppression. Mental health experiences of older adults living with HIV could be examined using a number of models that integrate social factors housing, employment, and working conditions, as 
well as gender, race, age, and social exclusion - in an understanding of overall health and mental health (Raphael, 2004; Tew, 2005). Future research may wish to draw on elements of structural social work approaches to mental health (Schwartz \& O'Brien, 2010; Towns \& Schwartz, 2012), which consider the significant impact of oppression based on class, gender, race, and sexual orientation, all of which interweave to contribute significantly to mental distress among older adults who are living with HIV.

Clear gaps exist in the knowledge about what constitutes typical aging versus aging with HIV. We need to do more to address these gaps in training, education, and systems of care. It is essential for people working in HIV and/or aging issues to better understand the intersection of the two fields, as this is the unique social location in which older adults living with HIV who seek mental health services may exist. Professional service providers will need to develop new ways to address mental health in the context of aging with HIV, and working with PLWHIV as mental health consumers - a vitally important piece of the puzzle.

Additionally, it is important for people working in this field to understand the effect of the multiple losses of life during the early days of the epidemic among older gay men who may be particularly sensitive to posttraumatic stress (Halkitis, 2013). Processing of grief, survivorship, changing expectations, and planning around longevity are particularly important considerations in mental health work with older PLWHIV and should be further studied. Differences between mental health outcomes of people diagnosed with HIV / AIDS at different points in the epidemic should also be factored into future studies. Additionally, more research about spirituality among this age group of PLWHIV is needed (Siegel \& Scrimshaw, 2002; Vance, Brennan, Enah, Smith, \& Kaur, 2011).

This study frames uncertainty and stigma as major barriers to mental health, and describes participants' unique coping strategies, which we have framed as individual approaches to resilience. Our findings identify the need for further research regarding the intersection of HIV / AIDS, aging, and mental health.

\section{References}

Antiretroviral Therapy Cohort Collaboration. (2008). Life expectancy of individuals on combination antiretroviral therapy in high-income countries: A collaborative analysis of 14 cohort studies. The Lancet, 372, 293-299.

Ascah, A. (2015). Ottawa HIV counselling service shutting down. DailyXtra. Retrieved from http:// www.dailyxtra.com/ottawa/news-and-ideas/news / ottawa-hiv-counselling-service-shutting-109609
Becker, J. T, Lopez, O. L., Dew, M. A., \& Aizenstein, H. J. (2004). Prevalence of cognitive disorders differs as a function of age in HIV virus infection. AIDS, 18(Suppl. 1), S11-S18.

Blanco, J. R., Jarrín, I., Vallejo, M., Berenguer, J., Solera, C., \& Rubio, R. (2012). Definition of advanced age in HIV infection: Looking for an age cut-off. AIDS Research and Human Retroviruses, 28(9), 1000-1006.

Brashers, D. E., Neidig, J. L., Reynolds, N. R., \& Haas, S. M. (1998). Uncertainty in illness across the HIV/AIDS trajectory. Journal of the Association of Nurses in AIDS Care, $9(1), 66-77$.

Brennan, D. J., Jackson, R., Zoccole, A., Nobis, T., Brett, C., \& Georgievski, G. (2015). Understanding the seven truths of resilience: Findings from the two-spirit HIV/AIDS wellness and longevity study (2SHAWLS), Ontario, Canada [Abstract]. Oral presentation at the Society for Social Work and Research Annual Conference, New Orleans, LA.

Brennan, M., \& Karpiak, S. E. (2009). "HIV stigma and disclosure of serostatus." In M. Brennan, S. E. Karpiak, R. A. Shippy, \& M. H. Cantor (Eds.), Older Adults with HIV: An In-depth Examination of an Emerging Population (pp. 33-50). New York, NY: Nova Science.

Cain, R., Lush, J., Bacon, J., Rueda, S., Collins, E., Mascarenhas, A., \& Robertson, S. (2013). Everything to everybody? An environmental scan of support services provided by AIDS service organizations in Ontario. Toronto, ON: Ontario HIV Treatment Network.

Charmaz, K. (1991). Good days, bad days: The self in chronic illness and time. New Brunswick, NJ: Rutgers University Press.

Corrigan, P. (2004). How stigma interferes with mental health care. American Psychologist, 59(7), 614-625.

Crawford, A. M. (1996). Stigma associated with AIDS: A metaanalysis. Journal of Applied Social Psychology, 26, 398-416.

Davies, M. L. (1997). Shattered assumptions: Time and the experience of long-term HIV positivity. Social Science $\mathcal{E}$ Medicine, 44(5), 561-571.

Effros, R. B., Fletcher, C. V., Gebo, K., Halter, J. B., Hazzard, W. R., McFarland Horne, F., ... High, K. P. (2008). Workshop on HIV infection and aging: What is known and future research directions. Clinical Infectious Diseases, $47(4), 542-553$.

Eldeman, E. J., Tetrault, J. M., \& Fiellin, D. A. (2014). Substance use in older HIV-infected patients. Current Opinion on HIV/AIDS, 9, 317-324.

Emlet, C.A. (2006). "You're awfully old to have this disease": Experiences of stigma and ageism in adults 50 years and older living with HIV/AIDS. The Gerontologist, 46(6), 781-790.

Emlet, C. A., Brennan, D. J., Brennenstuhl, S., Rueda, S., Hart, T. A., \& Rourke, S. B. (2015). The impact of HIV-related stigma on older and younger adults living with HIV disease: Does age matter? AIDS Care, 27(4), 520-528. 
Emlet, C. A., Fredriksen-Goldsen, K. I., \& Kim, H.-J. (2013). Risk and protective factors associated with health-related quality of life among older gay and bisexual men living with HIV disease. The Gerontologist, 53(6), 963-972.

Emlet, C. A., Harris, L., Furlotte, C., Brennan, D. J., \& Pierpaoli, C. (in press). "I'm happy in my life now, I'm a positive person": Approaches to Successful Aging in Older Adults Living with HIV. Ageing and Society. FirstView Article. doi:10.1017/S0144686X16000878

Emlet, C. A., Tozay, S., \& Raveis, V. (2011). “I'm not going to die from the AIDS": Resilience in aging with HIV disease. The Gerontologist, 51, 101-111.

Fang, X., Vincent, W., Calabrese, S. K., Heckman, T. G., Sikkema, K. J., Humphries, D. L., \& Hansen, N. B. (2015). Resilience, stress, and life quality in older adults living with HIV / AIDS. Aging and Mental Health, 30, 1-7.

Furlotte, C. (2009). Health and social service experiences of eleven older adults living with HIV/AIDS in the National Capital Region (Poster P266) [Abstract]. Canadian Journal of Infectious Diseases $\mathcal{E}$ Medical Microbiology 20, Suppl. SB, 84B.

Furlotte, C., Schwartz, K., Koornstra, J. J., \& Naster, R. (2012). "Got a room for me?" Housing experiences of older adults living with HIV in Ottawa, Ontario. Canadian Journal on Aging, 31(1), 37-48.

Green, G., \& Platt, S. (1997). Fear and loathing in health care settings reported by people with HIV. Sociology of Health and Illness, 19(1), 70-92.

Goffman, E. (1963). Stigma: Notes on the management of spoiled identity. Englewood Cliffs, NJ: Prentice-Hall.

Golub, S. A., \& Gamarel, K. E. (2013). The impact of anticipated HIV stigma on delays in HIV testing behaviors: Findings from a community-based sample of men who have sex with men and transgender women in New York City. AIDS Patient Care and STDs, 27(11), 621-627.

Grov, C., Golub, S. A., Parsons, J. T., Brennan, M., \& Karpiak, S. E. (2010). Loneliness and HIV-related stigma explain depression among older HIV-positive adults. AIDS Care: Psychological and Socio-medical Aspects of AIDS/HIV, 22(5), 630-639.

Halkitis, P. (2013). The AIDS Generation: Stories of Survival and Resilience. New York, NY: Oxford University Press.

Heckman, T. G., Kochman, A. K., \& Sikkema, K. J. (2004). Depressive symptoms in older adults living with HIV disease: Application of the chronic illness quality of life model. In C. A. Emlet (Ed.), HIV and older adults: Challenges for individuals, families and communities. (pp. 37-54). New York, NY: Springer.

Heckman, T. G., Kochman, A., Sikkema, K. J., \& Kalichman, S. C. (1999). Depressive symptomatology, daily stressors, and ways of coping among middle-age and older adults living with HIV disease. Journal of Mental Health and Aging, 5(4), 311-322.
Herek, G. M. (1999). AIDS and stigma. American Behavioral Scientist, 42(7), 1102-1112.

Herek, G. M., Mitnick, L., \& Burris, S. (1998). AIDS and stigma: A conceptual framework and research agenda. AIDS Public Policy Journal, 13(1), 36-47.

High, K. P., Brennan-Ing, M., Clifford, D. B., Cohen, M. H., Currier, J., Deeks, S. G. ... Volberding, V. (2012). HIV and Aging: State of Knowledge and Areas of Critical Need for Research. A Report to the NIH Office of AIDS Research by the HIV and Aging Working Group. Journal of Acquired Immune Deficiency Syndromes, 60(1). S1-18.

Hill Collins, P. (1998). Intersections of race, class, gender and nation: Some implications for Black family studies. Journal of Comparative Family Studies, 29(1), 27-36.

Hutchinson, E. D. (2005). The life course perspective: A promising approach for bridging the micro and macro worlds for social workers. Families in Society, 86(1), 143-152.

Justice, A. C. (2010). HIV and aging: Time for a new paradigm. Current HIV/AIDS Reports, 7(20), 69-76.

Karpiak, S. E., Shippy, R. A., \& Cantor, M. H. (2006). Research on older adults with HIV. New York, NY: AIDS Community Research Initiative of America.

Kirby, M. J. L., \& Keon, W. J. (2006). Out of the shadows at last: Transforming mental health, mental illness and addiction services in Canada. Ottawa, ON: Standing Senate Committee on Social Affairs, Science and Technology. Retrieved from www.parl.gc.ca/39/1/parlbus/commbus/senate/ com-e/soci-e/rep-e/rep02may06-e.htm

Leland, J. (2013, June 1). "People think it's over" spared death, aging people with H.I.V. struggle to live. The New York Times. Retrieved from http://www.nytimes. com/2013/06/02/nyregion/spared-death-aging-peoplewith-hivstruggle-to-live.html

Luthar, S. S. (2000). The construct of resilience: A critical evaluation and guidelines for future work. Child Development, 71(3), 543-562.

MacCourt, P., Wilson, K., \& Tourigny-Rivard, M.-F. (2011). Guidelines for Comprehensive Mental Health Services for Older Adults in Canada. Calgary, AB: Mental Health Commission of Canada. Retrieved from http://www. mentalhealthcommission.ca

Masten, A. S., Best, K. M., \& Garmezy, N. (1990). Resilience and development: Contributions from the study of children who overcame adversity. Development and Psychopathology, 2, 425-444.

Mavandadi, S., Zanjani, F., Ten Have, T. R., \& Oslin, D. W. (2009). Psychological well-being among individuals aging with HIV: The value of social relationships. Journal of Acquired Immune Deficiency Syndromes, 51(1), 91-98.

Owen, G., \& Catalan, J. (2012). "We never expected this to happen": Narratives of ageing with HIV among gay men living in London, UK. Cultural, Health and Sexuality, 14(1), 59-72. 
Pathai, S., Bajillan, H., Landay, A. L., \& High, K. P. (2014). Is HIV a model of accelerated or accentuated aging? Journals of Gerontology: A Biological Sciences Medical Sciences. 69(7), 833-842. doi:10.1093/gerona/glt168

Public Health Agency of Canada (PHAC). (2010). HIV/ AIDS Epi Update-July 2010: HIV among older Canadians. Retrieved from http:/ /www.phac-aspc.gc.ca/aids-sida/ publication/epi/2010/pdf/EN_Chapter6_Web.pdf

Public Health Agency of Canada, (2014). HIV and AIDS in Canada: Surveillance Report to December 31st, 2013. Retrieved from http://www.phac-aspc.gc.ca/aids-sida/ publication/survreport/2013/dec/index-eng.php

Public Health Agency of Canada. (2016). Mental Illness. Retrieved from http:/ /www.phac-aspc.gc.ca/cd-mc/ mi-mm/index-eng.php

Raphael, D. (2004). Social determinants of health: A Canadian perspective. Toronto, ON: Canadian Scholar's Press.

Regehr, C., \& Glancy, G. (2010). Mental Health Social Work Practice in Canada. Toronto, ON: Oxford University Press.

Remis, R. S., Swantee, C., \& Liu, K. (2009). Report on HIV/ AIDS in Ontario-2007. Toronto, ON: Ontario HIV Epidemiological Monitoring Unit.

Rinken, S. (2000). The AIDS crises and the modern self: Biographical self-construction in the awareness of finitude. Dordrecht, NLD: Kluwer Academic Press.

Robertson, K., Bayon, C., Molina, J.-M., McNamara, P., Resch, C., Muñoz-Moreno, J.A., ... van Wyk, J. (2014). Screening for neurocognitive impairment, depression, and anxiety in HIV-infected patients in Western Europe and Canada. AIDS Care: Psychological and Socio-medical Aspects of AIDS/HIV , 26(12), 1555-1561.

Roger, K., Mignone, J., \& Kirkland, S. (2013). Social aspects of aging with HIV. Canadian Journal of Aging, 32(3), 298-306.

Rosenfeld, D., Ridge, D., Von Lob, G., and On Behalf of the HIV and Later Life Team. (2014). Vital scientific puzzle or lived uncertainty? Professional and lived approached to uncertainties of ageing with HIV. Health Sociology Review, 23(1), 20-32.

Rueda, S., Law, S., \& Rourke, S. B. (2014). Psychosocial, mental health, and behavioral issues of aging with HIV. Current Opinion on HIV/AIDS, 9, 325-331.

Samji, H., Cescon, A., Hogg, R. S., Modur, S. P., Althoff, K. N., Buchacz, K., ... Gange, S. J. (2013). Closing the gap: Increases in life expectancy among treated HIV-positive individuals in the United States and Canada. PLOS ONE, 8(12): e81355. doi: 10.1371/journal.pone.0081355

Schwartz, K., \& O’Brien, A. M. (2010). Injustice can happen whether you're psychotic or not: Incorporating structural social work theory in a mental health setting. In S. Hick, H. Peters, and T. Corner (Eds.), Structural Social Work in Action: Examples from Practice (pp. 106-120). Toronto, ON: Canadian Scholars Press.
Scott, S., \& Constantine, L. M. (1999). The Lazarus syndrome: A second chance for life with HIV infection. Journal of the American Pharmaceutical Association, 39(4), 462-466.

Senate Special Committee on Aging (2013). Testimony of Daniel Tietz. Older Americans: The changing face of HIV/ AIDS in America. Report of the Senate Special Committee on Aging, 113th Congress.

Siegel, K., Dean, L., \& Scrimshaw, E. W. (1999). Symptom ambiguity among late-middle-aged and older adults with HIV. Research on Aging, 21(4), 595-618.

Siegel, K. \& Scrimshaw, E. W. (2002). The perceived benefits of religious and spiritual coping among older adults living with HIV/AIDS. Journal for the Scientific Study of Religion, 41(1), 91-102.

Siegel, K., Schrimshaw, E. W., \& Dean, L. (1999). Symptom interpretation and medication adherence among late middle-age and older HIV-infected adults. Journal of Health Psychology, 4(2), 247-257.

Smith, G. C., \& Hayslip, B., Jr. (2012). Annual review of gerontology $\mathcal{E}$ geriatrics. Volume 32: Emerging perspectives on resilience in adulthood and later life. New York, NY: Springer.

Solomon, P., O’Brien, K., Wilkins, S., \& Gervais, N. (2013). Aging with HIV and disability: The role of uncertainty. AIDS Care, 26(2), 240-245.

Squire, C. (2013). Living with HIV and ARVs: Three letter lives. London, ENG: Palgrave.

Tew, J. (2005). Social perspectives in mental health. Philadelphia, PA: Jessica Kingsley.

Topolski, J. M. (2002). Older adults, substance use, and HIV / AIDS: Preparing for a future crisis. Journal of Mental Health and Aging, 8(4), 349-363.

Towns, A., \& Schwartz, K. (2012) "Role of Social Work in a Mental Health Setting: Secondary Analysis of the Canadian Community Health Survey, Cycle 1.2 Mental Health and Well-being". Research on Social Work Practice, 22(2), 214-218.

Tutty, L. M., Rothery, M. A., \& Grinnell, R. M. (1996). Qualitative research for social workers. Toronto, ON: Allyn \& Bacon.

Valcour, V. G., \& Sacktor, N. (2002). HIV-associated dementia and aging. Journal of Mental Health and Aging, 8(4), 295-306.

Vance, D. E., Brennan, M., Enah, C., Smith, G. L., \& Kaur, J. (2011). Religion, spirituality, and older adults with HIV: Critical personal and social resources for an aging epidemic. Clinical Interventions in Aging, 6, 101-109.

Wallach, I., \& Brotman, S. (2013). Ageing with HIV / AIDS: A scoping study among people aged 50 and over living in Quebec. Ageing and Society, 33, 1212-1242.

Wendelken, L. A., \& Valcour, V. (2012). Impact of HIV and aging on neuropsychological function. Journal of NeuroVirology, 18(4), 256-263. 